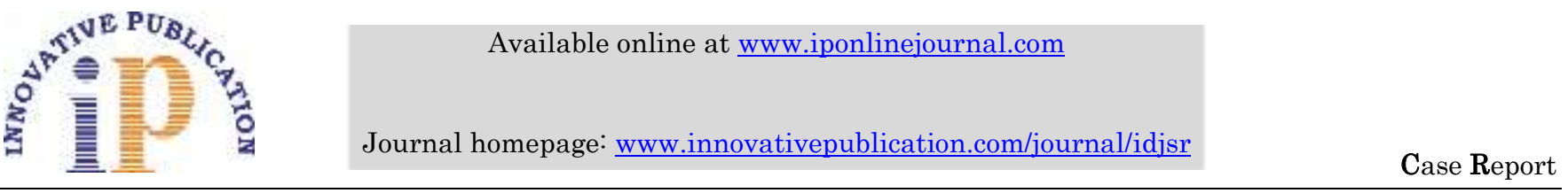

\title{
MAS (Mixture of Antibiotic and Steroid) paste - A novel drug combination in treating large periradicular lesions nonsurgically
}

\author{
Anusree M $\mathbf{P}^{1^{*}}$, Varunji M $\mathbf{S}^{2}$, Jackson $\mathrm{V} \mathrm{J}^{3}$ \\ Student, Royal Dental College, Palakkad, Kerala, India
}

\begin{abstract}
The current philosophy in the management of periapical lesions includes the initial use of nonsurgical methods. The surgical approach can be adopted for cases refractory to nonsurgical treatment, in obstructed or nonnegotiable canals and for cases where long term monitoring of periapical lesions is not possible. Many antibiotic combinations were used as intracanal medicament. Here report two cases managed uneventfully by using a newer drug combination. Clinically and radio graphically healing was reported within 3 months short duration. This combination was tried not only in cases with apical pathology but also cases with severe pain even after proper shaping and cleaning. It alleviates inflammatory pain and makes the patients asymptomatic and comfortable.
\end{abstract}

Keywords: MAS (Mixture of Antibiotics and Steroid), Granuloma, Cyst, Periapical, Ciplox eye drop, Flagyl, Dexona.

\section{Introduction}

Periapical lesion results from serious inflammatory response to microorganisms around the tooth root and the root canal. ${ }^{1}$ They often occur without any episode of acute pain and are discovered on routine radiographic examination. Most periapical lesions $(>90 \%)$ can be classified as dental granulomas, radicular cysts or abscesses. ${ }^{2,3}$ The incidence of cysts within periapical lesions varies between 6 and 55\%. The occurrence of periapical granulomas ranges between 9.3 and $87.1 \%$, and of abscesses between 28.7 and $70.07 \%$. $^{5}$

The ultimate goal of endodontic therapy should be to return the involved teeth to a state of health and function without surgical intervention. ${ }^{6}$ All inflammatory periapical lesions should be initially treated with conservative nonsurgical procedures. ${ }^{7}$ When this treatment approach is not successful a surgical approach may be adopted. ${ }^{8}$

The greatest challenge in root canal treatment is the complete elimination of infectious microorganisms within the root canal and from its peri radicular area. Mechanical instrumentation alone is unable to completely eradicate the polymicrobial infection from the root canal system. Therefore some sort of chemical disinfection by irrigation and intracanal medicament is necessary to optimally disinfect the root canal system. Wide range of intracanal medicaments with antibacterial properties were used in root canal treatments.

This case report demonstrated resolution of periapical pathologies achieved through a newer combination of intra canal medicament (MAS PASTE).This drug combination have been advocated to help in alleviating pain, inflammatory response also induce periapical healing within a short period of time.

\section{Case Reports I}

A 15 year old boy reported to the department of conservative dentistry and endodontics,royal dental college, Palakkad with a chief complaint of severe pain and swelling in lower front tooth region since I week. Patient gave the history of trauma about 6 years back.

On intraoral examination, a large swelling $(4 \times 5 \mathrm{~mm}$ in size) seen on floor of the mouth in the anterior region. The entire four lower anterior teeth were tender to vertical percussion. Grade II mobility of central incisors and Grade I mobility of two lateral incisors were positive. There is no sinus opening or pus discharge.

Intra oral periapical radiograph revealed diffuse radiolucency of size $10 \times 9 \mathrm{~mm}$ involving $41,42,31$ and 32 . Borders of the lesion appeared ill defined. Loss of lamina Dura was evident. Findings suggestive of large periapical abscess.

Thermal and electric pulp tests were performed to determine the vitality of the entire lower anterior tooth. The entire tooth shows a negative response to both electric and thermal test. Conventional root canal therapy was planned with MAS paste as intra canal medicament.

Following isolation with rubber dam, access cavity was prepared on mandibular central incisor. Immediate drainage accomplished through the canal of central incisors. The swelling was compressed and more fluid flowed out. Removal of necrotic pulp tissue was done after establishing the working length. Canal was instrumented up to $15-40 \mathrm{k}$ files (densply) and $\mathrm{H}$ files.Irrigation was carried out with $3 \%$ sodium hypochlorite solution and 17\% EDTA and saline. Patient send on open dressing for one day in order to facilitate drainage and patient reviewed in the next day itself to check the status of swelling.

\footnotetext{
*Corresponding Author: Anusree M P, Student, Royal Dental College, Palakkad, Kerala, India

Email: anusreeambadi@gmail.com

http://doi.org/10.18231/j.idjsr.2019.018
} 
Swelling slightly subsided but still patient have pain. Repeat the shaping and cleaning procedure and place MAS paste as intra canal medicament.

\section{Preparation of Mas (Mixture of antibiotic and steroid) paste}

The sugar coating of the Flagyl tablets were removed by scraping the outer surface and both Dexona $0.5 \mathrm{mg}$ and Flagyl 400mg were then grounded into fine powder using a mortar and pestle. The powered tablets were then weighed on a digital weighing machine in a ratio of 1:1 and mixed into a paste, where Ciplox eye drop were used as vehicle. Since Dexona is self desolving, preparation of a creamy mix is not time consuming.

Table 1

\begin{tabular}{|l|l|}
\hline Trade name & Components \\
\hline Ciplox eye drop & $\begin{array}{l}\text { Ciprofloxacin } \\
\text { +Dexamethasone }\end{array}$ \\
\hline Flagyl & Metrogyl 400mg \\
\hline Dexona & $0.5 \mathrm{mg}$ Dexamethasone \\
\hline
\end{tabular}

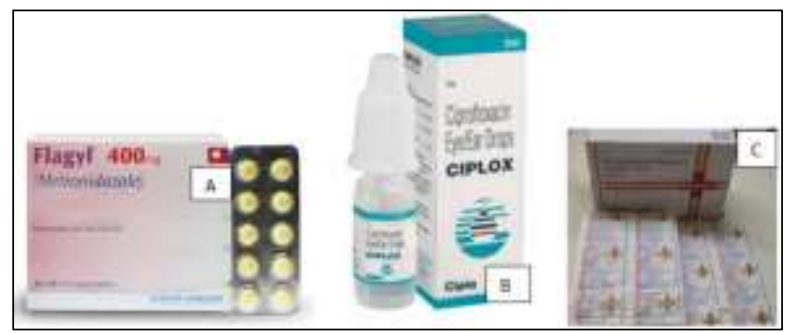

Fig. 1 A-C (Components of preparation) A - Flagyl 400mg; B. Ciplox eye drop; C. Dexona $0.5 \mathrm{mg}$

The canals were dried with sterile paper point and then medicament were palced into the canal using lentulospiral and $\mathrm{H}$ files. Acess cavity were sealed with Cavit with cotton pellet beneath the restoration. Patient reviewed after 1 week. Swelling and Symptoms completely subsided. Cleaning and shaping repeated with proper irrigation with $3 \%$ sodium hypochlorite and MAS paste given as intra canal medicament. Patient recalled after 2 week. Canals were cleaned with 3\%sodium hypochlorite and final rinse of $17 \%$ EDTA were given followed by normal saline. Canals were dried using paper points, and obturation of 41 and 31completed using lateral condensation technique.Obturation of 32 and 42 completed in the next visit after 1 week. Acess cavities of all the root canal treated tooth were sealed with GIC. Patient recalled after 3 months and 1 year interval.The clinical and radiographic examination demonstrated that patient was asymptomatic,and the tooth exhibit proper integrity of periapical and periodontal tissue after 1 year.

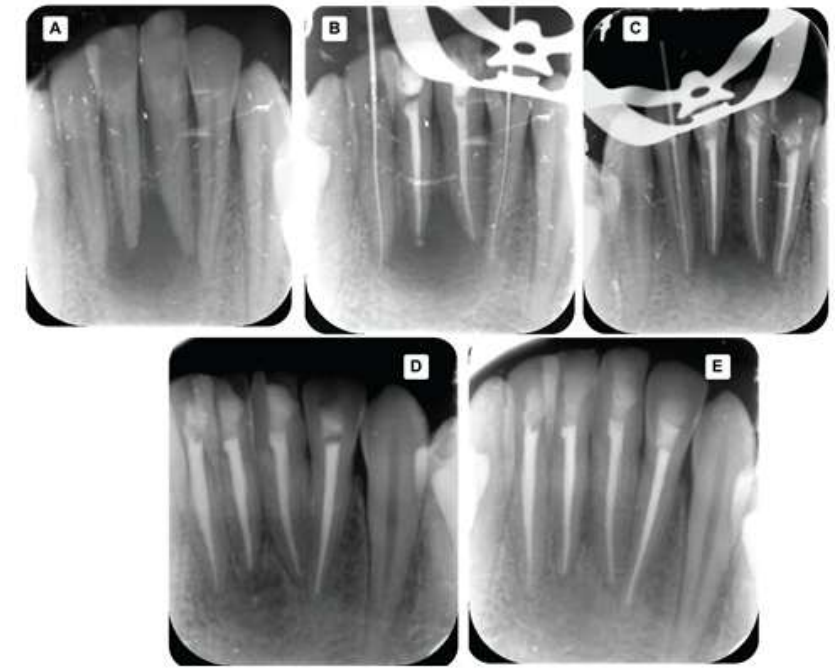

Fig. 2 A-E: A. Preoperative radiograph; B. Radiograph after 3 weeks; C. Radiograph after 4 week; D. Radiograph after 3 month; E. Radiograph after 1 year. (Case report 1)

\section{Case Report 2}

A 12 year old girl reported to department of Pedodontics and Preventive Dentistry with a chief complaint of pain in lower right back tooth region since 2 weeks. Her medical history was noncontributory. Pain history revealed a spontaneous, continuous, and dull type of pain which aggravated while taking food and during night times.

On intraoral examination, lower right first permanent molar revealed a deep carious lesion involving enamel, dentine and pulp. Tooth was tender to vertical percussion, with absence of mobility or extrusion from its socket. Gingiva overlying the buccal aspect of the tooth showed diffuse erythema and swelling, which was tender to percussion. Obliteration of buccal vestibule was noted. There was no sinus opening or pus discharge.

On extra oral examination, right mandibular lymph nodes were enlarged, firm, freely movable and tender to percussion.

Intra oral peri apical radiograph revealed diffuse coronal radiolucency of 46 involving enamel, dentin and pulp chamber. Well defined ovoid periapical radiolucency of size approximately $11 \mathrm{~mm}$ was noted.Borders of the lesion appeared ill defined mesially, well circumscribed inferiorly and slightly corticated distally. Internal structures showed sclerosed bone formation. Findings suggestive of infected pariapical cyst.

After evaluating all data non-surgical endodontic root canal treatment using new drug combination was planned.

Tooth was isolated with rubber dam and, access opening was done under Local anesthesia. Up on access, a thick purulent discharge extruded from the orifice of the canal. Canal orifices were located and working length radiograph was taken. The canals were instrumented using Protaper rotary files upon F1 in the mesial canals and up to F2 in the distal canal in the crown down technique. Apical patency clearance was done with no $10 \mathrm{k}$ file.During the instrumentation canal were irrigated with $35 \%$ sodium 
hypochlorite solution using a 27 gauge endodontic needle and $17 \%$ EDTA after each instrumentation.

In order to facilitate drainage patient send on open dressing and reviewed in the next day. ReBMP done on that visit.The canals were dried with sterile paper points and then MAS Paste was placed with a lentlospiral. The paste was further condensed using sterile cotton pellets before sealing the coronal access. Access opening was sealed with IRM.

The paste was changed every 2 weeks for a period of 3 months. 1 week following placement the medication the patient remained asymptomatic. After 3 month, radiograph revealed complete healing with well-defined trabecular pattern. Obuturation completed with thermoplastisized obturation technique during that visit.1 year review shows perfect healing in the periapical area.
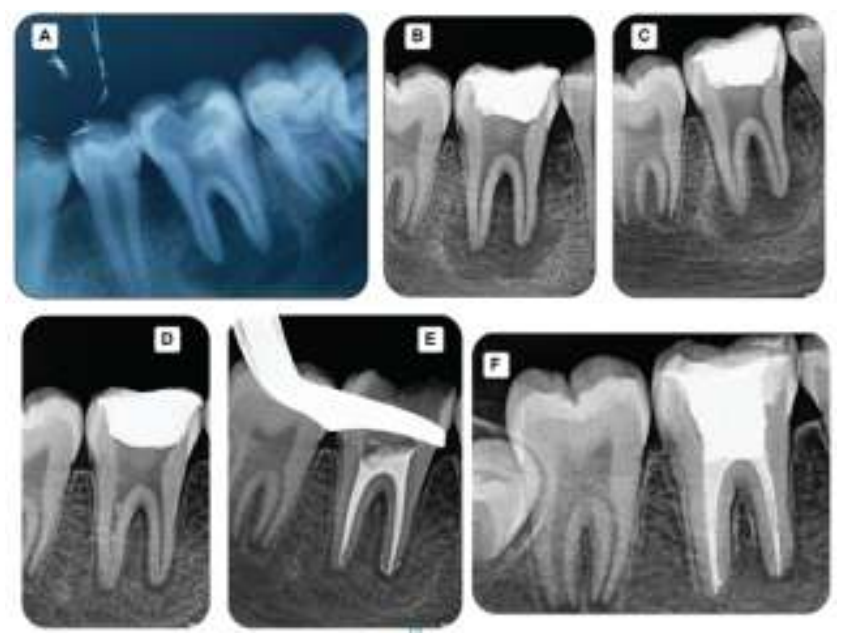

Fig. 3 A- F: A. Preoperative radiograph; B.1 week follow up radiograph; C. 3 Week follow up radiograph; D. 3 Month follow up radiograph; E. 3 month follow up radiograph after thermoplasticized obturation; F. 1 year follow up (Case report 2)

\section{Discussion}

In 1894 W.D. Miller suggested that bacteria were a possible cause of inflammation in pulp. The most common cause of pulpal injury is bacterial. Microorganisms need not be present in pulp to produce inflammation. By-products of bacteria in the dentine may be sufficiently irritating to cause an inflammatory reaction. ${ }^{9}$

In the past it was considered that large periapical lesions would not respond to root canal treatment alone and that surgery was always required. However, in recent years there is greater awareness of the root canal morphology and the development of newer instruments, techniques and materials has greatly enhanced the clinician's abilities. ${ }^{10}$

Disinfection of pulp space is an important step during and after cleaning and shaping. It primarily involves cleaning and shaping of root canal with endodontic instruments along with irritants. However, in certain clinical situations the polymicrobial nature of endodontic infection demands the use of an intracanal medicament in addition to the irritants. Intra canal medicaments are used for root canal disinfection as a part of controlled asepsis in an infected root canal. ${ }^{11}$ It has been proved that if the microbial load is reduced with an effective intracanal medicament, it is possible to stimulate the immunological system to induce repair, even in large lesions. ${ }^{12}$

The recommended regime for irrigation is to employ 17\% EDTA for 1 minute followed by a final rinse with $\mathrm{NaOCL},{ }^{13}$ which is followed saline irrigation. Irrigation with EDTA removes the smear layer. NaOCL is not only a pulp solvent and root canal irrigant, but it also has significant antimicrobial properties.

Calcium hydroxide has been considered the gold standard for optimally disinfecting root canals. ${ }^{10}$ However, its role in the elimination of the bacteria associated with persistent apical infections is controversial. Bacteria associated with persistent apical infections have the ability to invade the dentinal tubules and buffer the high $\mathrm{pH}$ produced by calcium hydroxide. ${ }^{14}$

Various nonsurgical methods have been used to treat periapical lesions which include Conservative Root Canal treatment without adjunctive therapy, decompression technique ${ }^{15}$ Aspiration irrigation therapy ${ }^{16}$ Apexum procedure $^{17}$ and Lesion Sterilization and tissue repair. ${ }^{18}$

The Cariology Research Unit of the Niigata University School of Dentistry has developed the concept of 'Lesion Sterilization and Tissue Repair (LSTR)' therapy. Repair of damaged tissues can be expected if lesions are disinfected. ${ }^{20}$ The combination of drugs has been shown to penetrate efficiently through dentine from the prepared root canals especially from the ultrasonically irrigated root canals. ${ }^{21}$ It is reported that the resulting sterilization with antibiotics or antiseptics result in approximately 20-40\%additional cleaning or augmenting the conventional root canal debridement. In this regard, various medicaments like antibiotics and antiseptics have been discussed. ${ }^{22}$

The systemic administration of antibiotics relies on patient compliance with the dosing regimens followed by absorption through the gastrointestinal tract and distribution via the circulatory system to bring the drug to the infected site. Hence the infected area requires a normal blood supply which is no longer the case for teeth with necrotic pulp and for teeth without pulp tissue. ${ }^{23}$ Local application of antibiotics may be a more effective mode for delivery in endodontics. Even in the present cases there was remarkable reduction in the symptoms after use of MAS paste with in 1 week and radiographic healing after 3 month.

The infection of the root canal system is considered to be a polymicrobial infection, consisting of both aerobic and anaerobic bacteria. Because of the complexity of the root canal infection it is unlikely that any single antibiotic could result in effective sterilization of the canal. More likely a combination would be needed to address the diverse flora encountered. A combination of antibiotics would also decrease the likelihood of the development of resistant bacterial strains. Alone, none of the drugs resulted in complete elimination of bacteria. However, in combination these drugs were able to consistently sterilize all samples 
[24]. An insitu study by Sato et $\mathrm{al}^{25}$ found that this drug combination was very effective in killing bacteria in the deep layers of root canal dentin.Since in small dose chances of toxicity can be minimized.

The present case report combine the effect of ciplox eye drop (consist of Ciprofloxacin and Dexamethasone), Dexona $0.5 \mathrm{mg}$ (Dexamethasone) and Flagyl 400mg (Metronidazole)

Systemic as well as local use of corticosteroid with or without antibiotics have been tried to prevent or reduce post treatment pain in endodontics. ${ }^{26}$ Smith et al stated that corticosteroids were effective in decreasing inflammation secondary to instrumentation. ${ }^{27}$ Local delivery of corticosteroid into the root canal may bring symptomatic relief from post instrumentation pain. It has also been recommended that pain associated with root canal treatment is reduced by gently forcing a corticosteroid preparation into periapical area. ${ }^{28}$ Schroeder recommended that antibiotics be used along with steroid in topical formulations to prevent the potential invasion of bacteria. ${ }^{29}$

Metronidazole is a nitroimidazole compound that exhibits broad spectrum of activity against protozoa and anaerobic bacteria. It is known for its strong antibacterial activity against anaerobic cocci, as well as gram- negative and gram-positive bacilli. It has been used both systemically and topically in the treatment of periodontal disease.

Ciprofloxacin, a synthetic floroquinolone, has a bactericidal mode of action. This bactericidal activity is not only during the multiplication phase, but also during the resting phase of the bacterium. Ciprofloxacin has very potent activity against gram-negative pathogens but very limited activity against gram-positive bacteria. Most anaerobic bacteria are resistant to Ciprofloxacin, therefore it is often combined with metronidazole in the treatment of mixed infections. When applied as an intra-canal medicament in low doses, adverse systemic side effects should be minimized. Periodic follow up examinations were essential while managing cases nonsurgically.

\section{Mechanism of Action of Ingradients in the combination}

Table 2

\begin{tabular}{|l|l|}
\hline Component & Mechanism \\
\hline Metrogyl & $\begin{array}{l}\text { Susceptible microorganisms reduce the } \\
\text { nitrogroup of metronidazole by a nitro } \\
\text { reductase and converts it to a cytotoxic } \\
\text { derivate which bind to DNA and inhibit } \\
\text { protein synthesis. It is strong against } \\
\text { anerobes. }\end{array}$ \\
\hline Ciprofloxacin & $\begin{array}{l}\text { Ciprofloxacin,a } \\
\text { floroquinolone,has a bactericidal mode } \\
\text { of action. It acts through the inhibition } \\
\text { of DNA gyrase, resulting in degradation } \\
\text { of the DNA by exonucleases. }\end{array}$ \\
\hline Dexamethasone & $\begin{array}{l}\text { Bind to specific site on DNA and } \\
\text { induce the synthesis of specific mRNA. } \\
\text { By this they regulate the synthesis of } \\
\text { new proteins. }\end{array}$ \\
\hline
\end{tabular}

\section{Conclusion}

The clinical cases reported in this article showed excellent healing of large periapical lesion achieved through a nonsurgical approach. Biological rationale for periapical pathology is pulpal in origin. Emphasis was laid on thorough debridement, disinfection of root canal system by MAS paste and three diamensional obturation of canal. The favorable and uneventful healing of the lesions with in short period of time confirm that periapical pathology respond perfectly to the newer combination of medicament. So a nonsurgical approach should always be adopted before resorting to surgery.

\section{Source of Funding}

None.

\section{Conflict of Interest}

None.

\section{References}

1. J. Singh, S. S. Amita Kumar, H. B. Singh, S. R. Singh, and B. Gill, "Healingo falarge periapicallesionusingtripleantibiotic paste and intracanal aspiration in nonsurgical endodontic retreatment. Indian J Dent 2014;161-5.

2. Bhaskar SN. Oral surgery--oral pathology conference No. 17, Walter Reed Army Medical Center. Periapical lesions--types, incidence, and clinical features. Oral Surg Oral Med Oral Pathol 1966;21:657-71.

3. Lalonde ER, Leubke RG. The frequency and distribution of periapical cysts and granulomas. Oral Surg Oral Med Oral Pathol 1986;25:861-8.

4. Nair PNR, Pajarola G, Schroeder HE. Types and incidence of human periapical lesions obtained with extracted teeth. Oral Surg Oral Med Oral Pathol Oral Radiol Endod 1996;81:93102.

5. Schulz M, von Arx T, Altermatt HJ, Bosshardt D. Histology of periapical lesions obtained during apical surgery. $J$ Endod 2009;35:634-42.

6. Salamat K, Rezai RF. Nonsurgical treatment of extraoral lesions caused by necrotic nonvital tooth. Oral Surg Oral Med Oral Pathol 1986;61:618-23.

7. Lin LM, Huang GT, Rosenberg PA. Proliferation of epithelial cell rests, formation of apical cysts, and regression of apical cysts after periapical wound healing. J Endod 2007;33:908-16.

8. Hoen MM, LaBounty GL, Strittmatter EJ. Conservative treatment of persistent periradicular lesions using aspiration and irrigation. J Endod 1990;16:182-6.

9. Grossmans Endodontic Practice 12 th edition.

10. Saatchi M. Healing of large periapical lesion: A non-surgical endodontic treatment approach. Aust Endod J 2007;33:136-40.

11. Grossman 272 page

12. Orstavik D, Kerekes K, Molven O. Effects of extensive apical reaming and calcium hydroxide dressing on bacterial infection during treatment of apical periodontitis: A pilot study. Int Endod J 1991;24:1-7.

13. Grossman 268

14. Adl A, Hamedi S, Sedigh Shams M, Motamedifar M, Sobhnamayan F. The ability of triple antibiotic paste and calcium hydroxide in disinfection of dentinal tubules. Iran Endod J 2014;9:123-6.

15. Loushine RJ, Weller RN, Bellizzi R, Kulild JC. A 2-day decompression: a case report of a maxillary first molar. $J$ Endod 1991;17(2):85-7. 
16. Hoen MM, LaBounty GL, Strittmatter EJ. Conservative treatment of persistent periradicular lesions using aspiration and irrigation. J Endod 1990;16(4):182-6.

17. Metzger Z, Huber R, Slavescu D, Dragomirescu D, Tobis I, Better $\mathrm{H}$ et al. Healing kinetics of periapical lesions enhanced by the apexum procedure: a clinical trial. $J$ Endod 2009;35(2):153-9.

18. Hoshino E. LSTR 3Mix-MP method-better and efficient clinical procedures of lesion sterilization and tissue repair (LSTR) therapy. Dent Rev 1998;666:57-106.

19. Fernandes M, de Ataide I. Nonsurgical management of periapical lesions. J Conserv Dent 2010;13(4):240.

20. Takushige T, Cruz EV, Moral AA, Hoshino E. Endodontic treatment of primary teeth using a combination of antibacterial drugs. Int Endod J 2004;37:132-8.

21. Sato I, Kurihara- Ando N, Kota K, Iwaku M, Hoshino E. Sterilization of infected root- canal dentine by topical application of a mixture of ciprofloxacin, metronidazole and minocycline in situ. Int Endod J 1996;29:118-24

22. Orstavik D, Haapasalo M. Invitro infection and disinfection of dentinal tubules. J Dent Res 1988;67(4):760. 1619 Duke St, Alexandria, Va 22314: Amer Assoc Dental Research.

23. Mohammadi Z, Abbott PV. On the local applications of antibiotics and antibiotic-based agents in endodontics and dental traumatology. Int Endod J 2009;42(7):555-67.
24. Windley III W, Teixeira F, Levin L, Sigurdsson A, Trope M. Disinfection of immature teeth with a triple antibiotic paste. $J$ Endod 2005;31(6):439-43.

25. Sato I, Ando-Kurihara N, Kota K, Iwaku M, Hoshino E. Sterilization of infected rootcanaldentinebytopicalapplicationofamixtureofciprofloxacin,me tronida- zole and minocycline in situ. Int Endod $J$ 1996;29:118-24.

26. Rogers MJ, Johnson BR, Remeikis NA, BeGole EA. Comparison of effect of intracanal use of ketorolac tromethamine and dexamethasone with oral ibuprofen on post treatment endodontic pain. J Endod 1999;25(5):381-4.

27. Smith RG, Patterson SS, El-Kafrawy AH. Histologic study of the effects of hydrocortisone on the apical periodontium of dogs. J Endod 1976;2(12):376-80.

28. Gurney BF. Clinical pharmacology in endodontics and intracanal medicaments. Dent Clin North Am 1974;18(2):25768.

29. Schroeder A. Corticosteriods in endodontics. J Oral Ther Pharmacol 1965;2:171-9.

How to cite this article: Anusree MP, Varunji MS, Jackson VJ. MAS (Mixture of Antibiotic and Steroid) paste - A novel drug combination in treating large periradicular lesions nonsurgically. Int Dent J Student Res 2019;7(3):70-4. 